\title{
Food Provision in a Paediatric Oncology unit: Patient Satisfaction and Food Waste
}

\author{
E. Ni Bhuachalla ${ }^{1}$, R. Kelly ${ }^{1}$, C. Mc Govern ${ }^{2}$, L. Oosthuizen ${ }^{2}$, I. Saul ${ }^{2}$ and S. Sugrue ${ }^{1}$ \\ ${ }^{1}$ Dublin Institute of Technology, Kevin Street, Dublin 8, Republic of Ireland and ${ }^{2}$ Department of Clinical Nutrition and \\ Dietetics, Our Lady's Children's Hospital, Crumlin, Dublin 12, Republic of Ireland
}

Food service provision in a Paediatric Oncology setting is complex due to the many nutritional challenges faced by these patients as a consequence of cancer and its intensive treatments. Appropriate food service provision is essential in ensuring these patients receive adequate nutrition. Adequate nourishment is associated with enhanced immune function, reduced length of hospital stay and improved recovery and quality of life in this patient group ${ }^{(1)}$. Auditing food service provision can help identify priorities for service improvement. This study aimed to investigate patient/parent satisfaction with current food provision, to assess food waste at mealtimes and to identify possible areas for service development.

A total of 66 parents/patients who were either inpatients or day-cases attending the day ward, completed a self-administered questionnaire, an adapted version of the validated Acute Care Hospital Food Service Patient Satisfaction Questionnaire ${ }^{(2)}$, modified for use in the paediatric oncology setting. Participants must have had consumed at least one meal provided by the hospital food service, either on a current or on a previous hospital admission. Patient satisfaction with five core food service dimensions; food quality, meal service quality, food quantity, staff/service issues and the physical environment, was determined using mean satisfaction scores ${ }^{(3)}$. Food waste was measured by weighing bulk food on its delivery to the unit and following the food service. Uneaten food waste was measured by weighing food before delivery to the patient and after its collection.

\begin{tabular}{lc}
\hline Foodservice Dimension & Mean Satisfaction Score \\
\hline Food Quality & 2.79 \\
Meal Service Quality & 3.15 \\
Food Quantity & 2.56 \\
Staff/Service issues & 4.52 \\
Physical Environment & 3.43 \\
Overall Satisfaction & 3.14 \\
\hline
\end{tabular}

The mean overall satisfaction score was representative of 'okay'-'good' satisfaction ratings. Staff/service issues was the highest scoring dimension while food quality and food quantity were the lowest scoring dimensions. Areas identified for service improvement included expansion of menu choices, introduction of a snack-service and timely provision of food service information to service-users.

Mean satisfaction scores on a scale of 1.00-5.00 corresponding to 'very poor' -'very good' satisfaction ratings.

On the 11-bed inpatient ward, a total of $120.4 \mathrm{~kg}$ of food waste was generated between dinnertime and suppertime meals over the 12 days of data collection, representing $86 \%$ of all food delivered to the ward. Of this $120.4 \mathrm{~kg}, 88.3 \mathrm{~kg}(73 \%)$ arose from food which was delivered to the ward but which was not served to patients (bulk waste). The remaining $32.1 \mathrm{~kg}(27 \%)$ of waste arose from food served to patients but which was not eaten (plate waste).

High levels of food waste were generated in the paediatric oncology setting; with levels found to be higher than those recorded in adult acute hospitals. Overall satisfaction scores also indicated suboptimal satisfaction with the food service. Although food service provision is particularly challenging in this patient group, positive alterations to current systems have the potential to greatly improve both patient satisfaction and food wastage levels. Such changes would facilitate the creation of an efficient, economic, patient-centred hospital food provision service.

1. Bauer J, Jürgens H \& Frühwald MC (2011) Important aspects of nutrition in children with cancer. Advances in nutrition (Bethesda, Md.) 2, 67-77.

2. Capra S, Wright O, Sardie M, Bauer J, Askew D (2005) The acute hospital foodservice patient satisfaction questionnaire: The development of a valid and reliable tool to measure patient satisfaction with acute care hospital foodservices. Foodservice Research International 16, 1-14.

3. Fallon A, Gurr S, Hannan-Jones M, Bauer JD (2008) Use of the Acute Care Hospital Foodservice Patient Satisfaction Questionnaire to monitor trends in patient satisfaction with the foodservice at an acute-care private hospital. Nutr Diet $\mathbf{6 5}, 41-46$. 